\title{
Enhancing Corrosion and Wear Resistance of AA6061 by Friction Stir Processing with $\mathrm{Fe}_{78} \mathrm{Si}_{9} \mathrm{~B}_{13}$ Glass Particles
}

\author{
Lingyu Guo ${ }^{1}$, Yan Liu ${ }^{1}$, Kechang Shen ${ }^{1}$, Chaoqun Song ${ }^{1}$, Min Yang ${ }^{1}$, Kibuem Kim ${ }^{2}$ and \\ Weimin Wang ${ }^{1, *}$
}

1 Key Laboratory for Liquid-Solid Structural Evolution and Processing of Materials, Ministry of Education, Shandong University, Jinan 250061, China;

E-Mails: guolingyusdu@gmail.com (L.G.); ly7623@sdjzu.edu.cn (Y.L.); kechangshsdu@gmail.com (K.S.); songchaoqun123@gmail.com (C.S.); miny@sdu.edu.cn (M.Y.)

2 Hybrid Materials Center (HMC), Faculty of Nanotechnology and Advanced Materials Engineering, Sejong University, 209 Neungdong-ro, Gwangjin-gu, Seoul 143-747, Korea; E-Mail: kbkim@sejong.ac.kr

* Author to whom correspondence should be addressed; E-Mail: weiminw@sdu.edu.cn; Tel.: +86-531-8839-2749; Fax: +86-531-8839-5011.

Academic Editor: Daolun Chen

Received: 5 July 2015 / Accepted: 31 July 2015 / Published: 7 August 2015

\begin{abstract}
The AA6061-T6 aluminum alloy samples including annealed $\mathrm{Fe}_{78} \mathrm{Si}_{9} \mathrm{~B}_{13}$ particles were prepared by friction stir processing (FSP) and investigated by various techniques. The $\mathrm{Fe}_{78} \mathrm{Si}_{9} \mathrm{~B}_{13}$-reinforced particles are uniformly dispersed in the aluminum alloy matrix. The XRD results indicated that the lattice parameter of $\alpha$-Al increases and the preferred orientation factors $F$ of (200) plane of $\alpha$-Al reduces after friction stir processing. The coefficient of thermal expansion (CTE) for FSP samples increases at first with the temperature but then decreases as the temperature further increased, which can be explained by the dissolving of $\mathrm{Mg}$ and $\mathrm{Si}$ from $\beta$ phase and $\mathrm{Fe}_{78} \mathrm{Si}_{9} \mathrm{~B}_{13}$ particles. The corrosion and wear resistance of FSP samples have been improved compared with that of base metal, which can be attributed to the reduction of grain size and the CTE mismatch between the base metal and reinforced particles by FSP, and the lubrication effect of $\mathrm{Fe}_{78} \mathrm{Si}_{9} \mathrm{~B}_{13}$ particles also plays a role in improving wear resistance. In particular, the FSP sample with reinforced particles in amorphous state exhibited superior corrosion and wear resistance due to the unique metastable structure.
\end{abstract}

Keywords: aluminum alloy; $\mathrm{Fe}_{78} \mathrm{Si}_{9} \mathrm{~B}_{13}$; friction stir processing; corrosion; wear 


\section{Introduction}

Aluminum and its alloys are used extensively in numerous fields due to their low densities and high strength to weight ratio [1,2]. Nevertheless, their poor resistance to wear and corrosion causes certain limitations for their application [3]. Metal matrix composites are a new type of material that exhibit good wear and corrosion resistance properties as compared to the matrix [4,5].

As wear and corrosion are surface-dependent degradation, they can be improved by a suitable modification of surface microstructure and/or composition. A proper technique can be employed to refine the microstructure and homogeneous dispersion of reinforcements on metallic surface. With conventional surface modification techniques it is difficult to improve the dispersion of reinforcement particles on the metal surface [6]. According to previous research [7,8], thermal spraying and laser beam techniques were used to prepare surface composites, but the creation of an unfavorable phase contributed to the degeneration of the properties. These techniques were operated at high temperature and it was difficult to avoid a reaction between the reinforcements and the matrix, which leads to the formation of an adverse phase. Thus, a fabrication process below the melting temperature of the matrix is critical to avoid the complications mentioned above.

Recently, friction stir processing (FSP), a successful surfaced modification technique derived based on the principles of friction stir welding (FSW) by Mishra et al. [9], has attracted much attention [10,11]. During the processing, a non-consumable rotating tool is plunged into the interface between two plates to be joined and traversed along the line of the joint with a specially designed pin and shoulder. The severe plastic deformation and material flow in the stirred zone can be utilized to achieve bulk alloy modification via mixing of other elements or the second phase into the stirred alloys, accompanied with significant grain refinement [9]. Friction stir processing is a solid state processing technique to obtain surface composites. In previous studies [12-15], the most widely used reinforcements are ceramics, such as $\mathrm{Al}_{2} \mathrm{O}_{3}$ or $\mathrm{SiC}$ in the conventional metal matrix composites. There is little research about using amorphous alloy as a reinforced material. The amorphous materials have superior properties such as high strength, high hardness, and excellent corrosion resistance due to their disordered and metastable structure [16-19].

In the present study, we focus on the development of a new AA6061-T6 alloy matrix reinforced with $\mathrm{Fe}_{78} \mathrm{Si}_{9} \mathrm{~B}_{13}$ particles, which are fabricated by a friction stir process. The microstructure, corrosion resistance, wear behavior, and magnetic properties of the composites and base metal are investigated by different techniques.

\section{Experimental Procedure}

In this study, the base metal employed is a $4 \mathrm{~mm}$ thick aluminum alloy AA6061-T6, which has a chemical composition of (in wt.\%) Mg: 0.95; Si: 0.54; Fe: 0.22; $\mathrm{Mn}: 0.13 ; \mathrm{Cu}: 0.17 ; \mathrm{Cr}: 0.09$; Zn: 0.08; Ni: 0.02; Ti: 0.01; Al: balance [20]. Using manual drilling machines we created a series of blind holes in the aluminum alloy surface, with a diameter and depth of $3 \mathrm{~mm}$. The reinforced particles are $\mathrm{Fe}_{78} \mathrm{Si}_{9} \mathrm{~B}_{13}$ metal glasses after annealing and high energy milling processes. The annealing temperatures are $300{ }^{\circ} \mathrm{C}$ and $700{ }^{\circ} \mathrm{C}$, respectively. The milling parameters are selected as following: the ratio of ball to powder is $10: 1$, frequency is $20 \mathrm{~Hz}$, and the milling temperature is $-196{ }^{\circ} \mathrm{C}$. The FSP machine was used for fabricating in situ hybrid surface composites. The parameters for FSP include a 
traveling speed (v) of $45 \mathrm{~mm} / \mathrm{min}$, a rotational rate (w) of $900 \mathrm{r} / \mathrm{min}$, a descending distance of $3 \mathrm{~mm}$, and four stirrings. The base metal and the composites reinforced with particles annealed at $300{ }^{\circ} \mathrm{C}$ and $700{ }^{\circ} \mathrm{C}$ were named S000, S300, and S700, respectively.

The phase components of samples were investigated by $\mathrm{X}$-ray diffractometer with $\mathrm{Cu}$ target (D/MAX 2500/PC, Rigaku, Tokyo, Japan, $\mathrm{Cu} \mathrm{K \alpha}, \lambda=0.154056 \mathrm{~nm}$ ) and Co target (X'Pert PRO, PANalytical, Almelo, the Netherlands, Co K $\alpha, \lambda=0.178897 \mathrm{~nm}$ ). The lattice constant is calculated by the extended Bragg equation [21]:

$$
a_{0}=\frac{\lambda}{2 \sin \theta} \sqrt{h^{2}+k^{2}+l^{2}}
$$

where $\lambda$ is the radiation wavelength; $\theta$ is the diffraction angle; and $h, k$, and $l$ are the crystal plane indices. In present samples, the preferred orientation factors $F$ of (200) plane of $\alpha$-Al are investigated by the Lotgering method [22]:

$$
F=\frac{P-P_{0}}{1-P_{0}}, P=\frac{\sum I_{(h 00)}}{\sum I_{(h k l)}} \text { and } P_{0}=\frac{\sum I_{0(h 00)}}{\sum I_{0(h k l)}}
$$

where $I_{(h 00)}$ and $I_{(h k l)}$ are the integral intensities of diffraction peaks for composites samples and randomly oriented samples, respectively; and $P$ and $P_{0}$ are the ratios of integral intensities of $(h 00)$ planes to those of all $(h k l)$ planes for composites samples and randomly oriented samples, respectively.

The microstructure of samples was examined by scanning electron microscopy (SEM, SUPRA55, Zeiss, Germany). Thermal expansion curves were measured by a dilatometer (DIL, Netzsch 402C, Netzsch, Shanghai, China) with a constant heating rate $20 \mathrm{~K} / \mathrm{min}$, performed under flowing high purity argon to protect the samples from oxidation.

The electrochemical measurements were carried out by $\mathrm{CHI} 660 \mathrm{E}$ advanced electrochemical workstation with a scanning rate of $1 \mathrm{mV} / \mathrm{s}$ at room temperature. There was a typical three-electrode system in electrochemical measurements: working electrode, platinum counter electrode and $\mathrm{Hg} \mid \mathrm{Hg}_{2} \mathrm{Cl}_{2}$ (SCE) reference electrode. The electrolyte is $3.5 \mathrm{wt} \% \mathrm{NaCl}$ solutions.

The wear behavior of the base metal and hybrid surface composites was measured using a wear apparatus (M-2000, Yinuo Testing Machine, Jinan, China) at room temperature. The wear test was conducted at a rotation rate of abrasive wheel of $200 \mathrm{r} / \mathrm{min}$, normal force of $120 \mathrm{~N}$, and sliding time of $10 \mathrm{~min}$.

\section{Results}

Figure 1a illustrates an overview of the side of the FSP plate in contact with the shoulder tool. This surface shows semicircular features, similar to those induced by a conventional milling process without cracking and other disfigure. The XRD patterns of the reinforced particles are also shown in Figure $1 \mathrm{~b}$, explaining that the particles annealed at $300{ }^{\circ} \mathrm{C}$ are in the amorphous state, and those annealed at $700{ }^{\circ} \mathrm{C}$ are in the crystalline state. Figure $1 \mathrm{c}, \mathrm{d}$ show the morphology of the samples with the reinforced particles annealing at $300{ }^{\circ} \mathrm{C}$ and $700{ }^{\circ} \mathrm{C}$, denoted as S300 and S700, respectively. It can be found that the reinforced particle is relatively uniform dispersed in the aluminum alloy matrix, and the size of the particle annealed at $700{ }^{\circ} \mathrm{C}$ is smaller than that of the particle annealed at $300{ }^{\circ} \mathrm{C}$. 
Figure 2 shows the XRD patterns of AA6061 FSP samples with Fe78SigB13 particles (S300 and S700) as well as the base alloy (denoted S000). The main diffraction peaks are $\alpha$-Al phases, and the other intermetallic phases are not found due to the less content. The (111), (200), (220), and (311) peaks of $\alpha-\mathrm{Al}$ are easily identified, and the intensity of the (200) peak changed obviously. The inset shows that the peak of diffraction $(2 \theta)$ of (200) plane of $\alpha$-Al in S300 shifts to the left after FSP. For clarity, the angle of

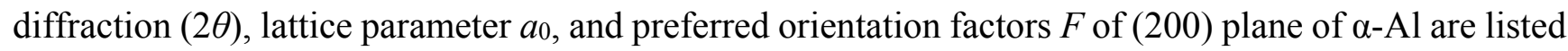
in Table 1. According to Equation (1), the lattice constants of the (200) plane of $\alpha$-Al for the three samples are in the order S300 $>$ S700 $>$ S000. However, the preferred orientation factors $F$ of the (200) plane of $\alpha-\mathrm{Al}$ for the samples are in the order S300<S700<S000, implying that the initial rolling texture was destroyed during friction stir processing. In addition, the variation of XRD data with the Co target is confirmed by that with the $\mathrm{Cu}$ target.
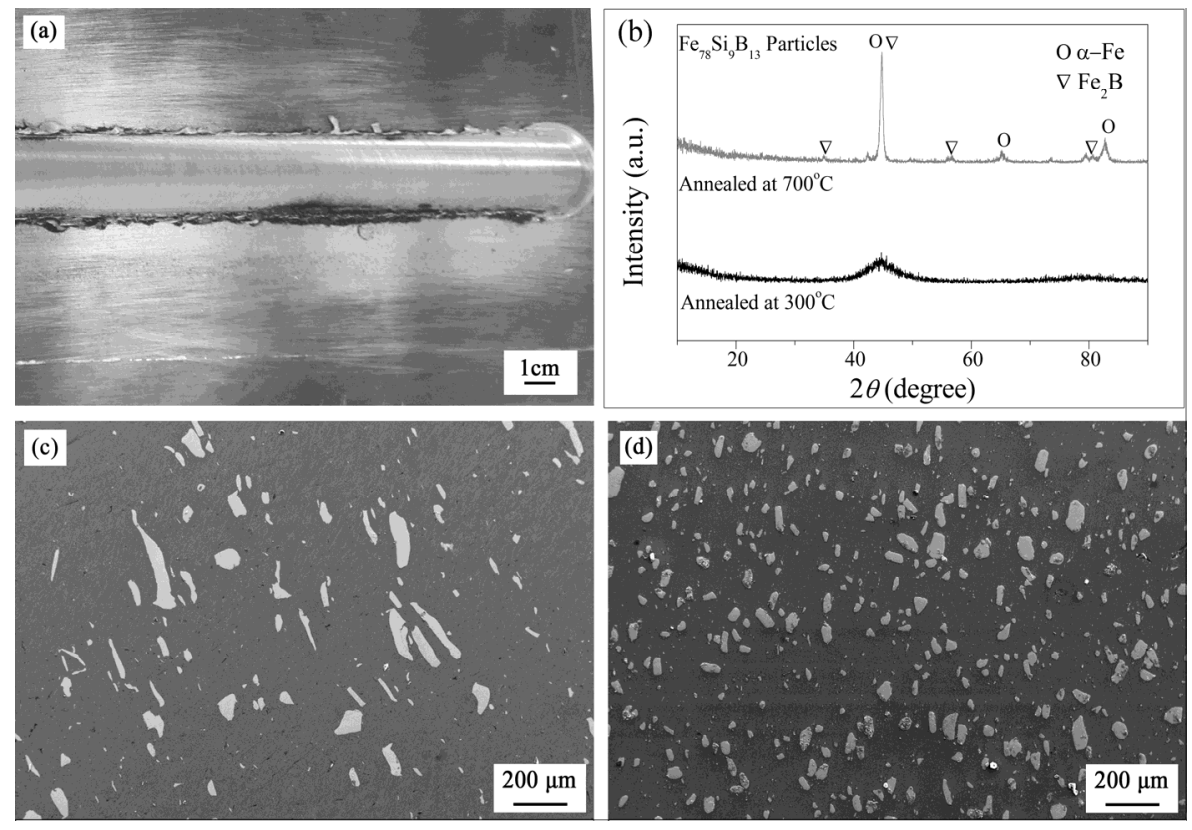

Figure 1. Topography of FSP samples: (a) Macrograph of samples after friction stir processing; (b) XRD patterns of the reinforced particles; (c) SEM photomicrograph of S300; (d) SEM photomicrograph of S700.

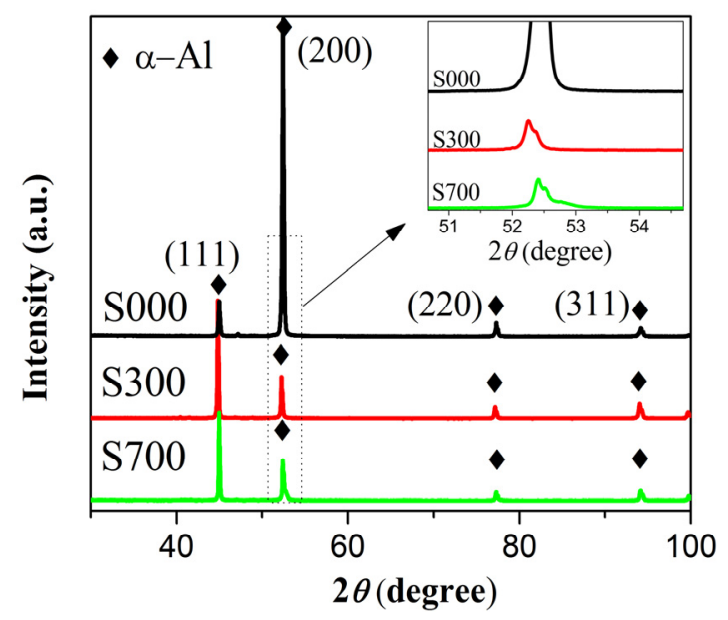

Figure 2. The XRD diffraction patterns for base metal (S000) and FSP samples (S300 and S700). 
Table 1. The preferred orientation factors $F$, lattice parameter $a_{0}$, and angle of diffraction $(2 \theta)$ of the (200) plane of $\alpha$-Al of samples obtained from X-ray diffraction.

\begin{tabular}{cccccc}
\hline Sample & $\boldsymbol{2} \boldsymbol{\theta}$ (degree) & $\boldsymbol{a}_{\mathbf{0}}$ (angstrom) & $\left(\boldsymbol{a}_{\mathbf{0}}-\boldsymbol{a}_{\mathbf{0}} *\right) / \boldsymbol{a}_{\mathbf{0}} * \mathbf{( \% )}$ & $\boldsymbol{F}$ & $\boldsymbol{F}^{\boldsymbol{Y}}$ \\
\hline S000 & 52.434 & 4.0495 & 0.003 & 0.7530 & 0.7462 \\
S300 & 52.252 & 4.0626 & 0.330 & 0.0031 & 0.0293 \\
S700 & 52.406 & 4.0515 & 0.052 & 0.1023 & 0.1009 \\
\hline
\end{tabular}

Notes: $2 \theta, a_{0}$, and $F$ were tested by the Co target; $F$ ' was tested by the $\mathrm{Cu}$ target; and $a_{0}{ }^{*}$ was the lattice constant of pure Al.

The thermal expansion curves and the variation of experimental coefficient of thermal expansions (CTE) obtained for base metal and FSP samples are shown in Figure 3. The three samples have an approximately linearly varying trend: the thermal expansion ratio increases with increasing temperature. In addition, the CTE of S000 increases with increasing temperature, but there is a plateau at about $300{ }^{\circ} \mathrm{C}$. By contrast, the CTE of FSP samples at first increases with the temperature but then decreases as the temperature is further increased, and the temperature at which the CTE begins to decrease for S300 is about $350{ }^{\circ} \mathrm{C}$, which is higher than that for $\mathrm{S} 700$, which is about $300{ }^{\circ} \mathrm{C}$. Furthermore, the maximal CTEs for S300 and S700 are $2.87 \times 10^{-5} \mathrm{~K}^{-1}$ and $3.04 \times 10^{-5} \mathrm{~K}^{-1}$, respectively, and that of S000 at platform is $2.71 \times 10^{-5} \mathrm{~K}^{-1}$, which is lower than the former values. Moreover, at $550{ }^{\circ} \mathrm{C}$, the CTE of $\mathrm{S} 000$ is about $3.18 \times 10^{-5} \mathrm{~K}^{-1}$, which is higher than that of $\mathrm{S} 300$ and $\mathrm{S} 700$, which are $2.48 \times 10^{-5} \mathrm{~K}^{-1}$ and $2.71 \times 10^{-5} \mathrm{~K}^{-1}$, respectively, i.e., in the order $\mathrm{S} 300<\mathrm{S} 700<\mathrm{S} 000$.

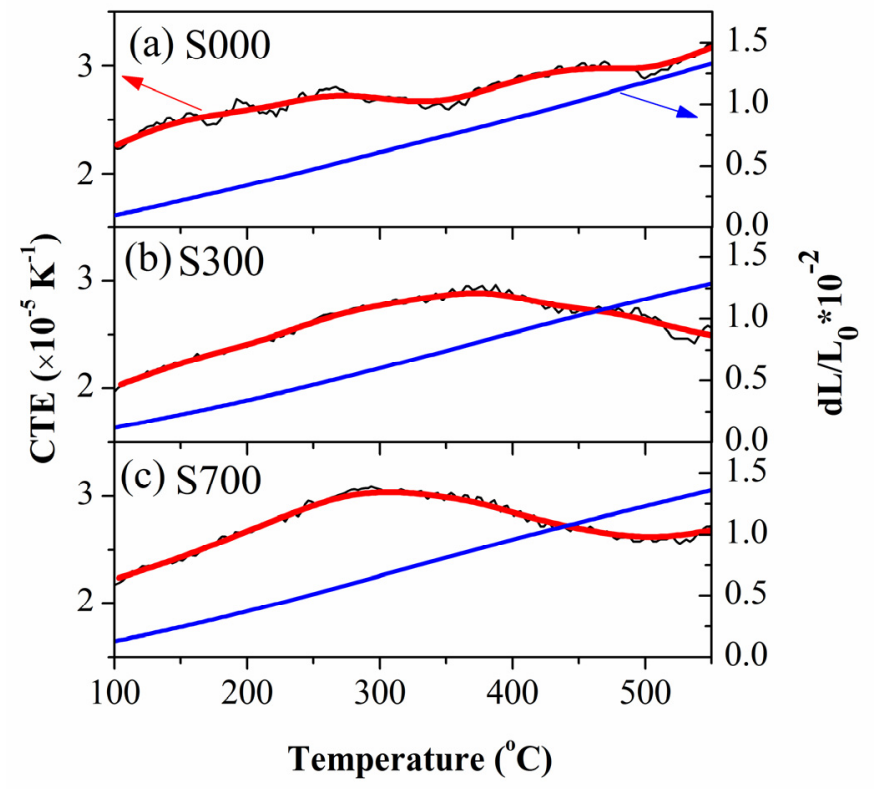

Figure 3. Thermal expansion curves (blue) and the variation of experimental coefficient of thermal expansions (CTE) (red) for (a) base metal (S000) as well as (b) S300 and (c) S700 FSP samples.

The cyclic anodic polarization curves of the base metal and FSP samples with a scanning rate of $1 \mathrm{mV} / \mathrm{s}$, obtained in $3.5 \mathrm{wt} \% \mathrm{NaCl}$ solutions, are shown in Figure 4. As can be seen from the curves, an obvious current plateau is observed in each curve, which is associated with passive film formation during the anodic polarization. The electrochemical parameters such as corrosion potential $\left(E_{\text {corr }}\right)$, corrosion current 
density $\left(i_{\text {corr }}\right)$, pitting potential $\left(E_{\mathrm{pit}}\right)$, protection potential $\left(E_{\mathrm{pp}}\right)$, and recorrosion current density $\left(i_{\text {rcorr }}\right)$ are collected in Figure 5 . The $E_{\text {corr }}$ of the three samples are also in the order $\mathrm{S} 300>\mathrm{S} 700>\mathrm{S} 000$, and $i_{\text {corr }}$ is quite the opposite, indicating that the anodic reaction of FSP samples occurs with more difficulty in the electrochemical test. Furthermore, the $E_{\mathrm{pit}}$ and $E_{\mathrm{pp}}$ of S300 and S700 are more positive than that of S000, and $\mathrm{S} 300$ has the highest $E_{\text {pit }}$ and $E_{\mathrm{pp}}$, which is consistent with the measured $E_{\text {corr. }}$ Here, the concept of protection potential $\left(E_{\mathrm{pp}}\right)$ represents the potential at which pre-existing pits cease to propagate, that is, all the propagating pits are repassivated [23]. The $E_{\mathrm{pit}}$ and $E_{\mathrm{pp}}$ are related to pitting corrosion resistance, and the higher $E_{\mathrm{pit}}$ and $E_{\mathrm{pp}}$ indicate higher resistance to pitting corrosion. The $i_{\text {rcorr }}$ represents the current density at which the samples incur corrosion after the repassivation region. The $i_{\text {rcorr }}$ of FSP samples is lower than base metal, and the $i_{\text {rcorr }}$ of S300 is the lowest, i.e., in the same order of $i_{\text {corr. }}$ Combined with the above measured electrochemical parameters, it is found that the corrosion resistance of the three samples is in the order S300 $>$ S700 $>$ S000.

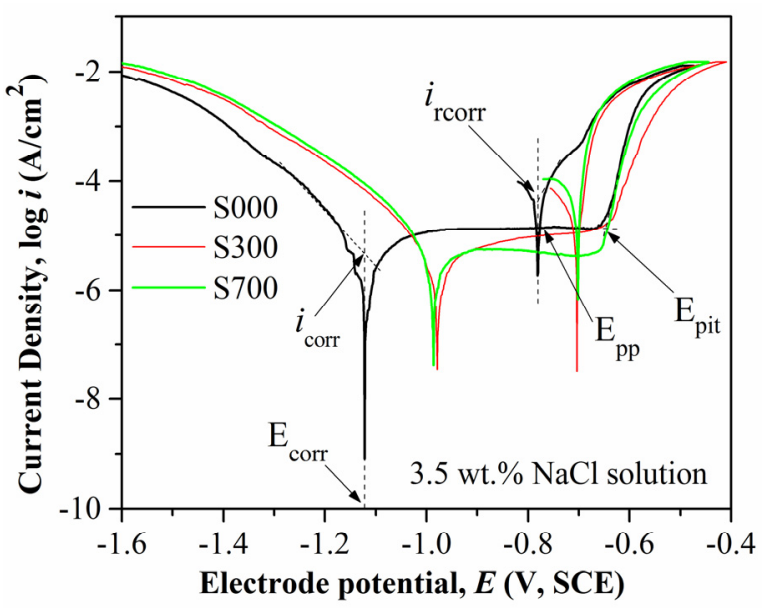

Figure 4. Cyclic anodic polarization curves of base metal (S000) and FSP samples (S300 and S700).

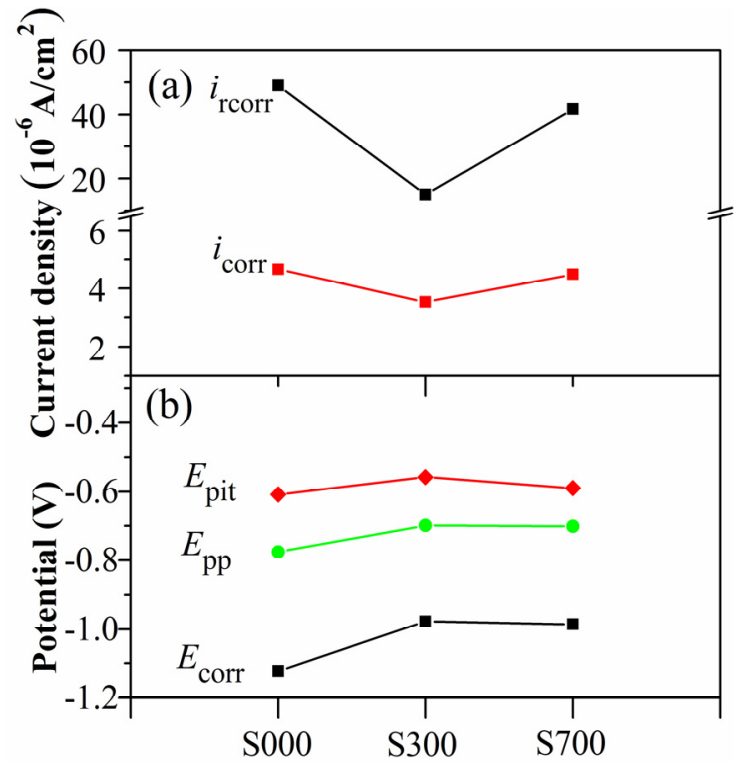

Figure 5. Parameters of the polarization obtained from Figure 4: (a) corrosion current density ( $\left.i_{\text {corr }}\right)$ and recorrosion current density $i_{\text {rcorr; }}$ (b) corrosion potential $\left(E_{\text {corr }}\right)$, pitting potential $\left(E_{\mathrm{pit}}\right)$ and protection potential $\left(E_{\mathrm{pp}}\right)$. 
The SEM images of electrochemical corroded surfaces of base metal and FSP samples are shown in Figure 6 . The measured samples were polarized until $-0.4 \mathrm{VSCE}$ with a scanning rate of $1 \mathrm{mV} / \mathrm{s}$ and without backward scanning (the polarization curves are not shown here). Many corrosion pits of $50 \mu \mathrm{m}$ in diameter appear on the surface of S000; by contrast, there are fewer corrosion pits of smaller size $(\sim 20 \mu \mathrm{m})$ on the surface of S300 and S700. With further investigation, the pits on the surface of S300 are shown to be much sparser than that of S700. The pits on the base metal are deeper than on the FSP samples, accompanied by obvious cracking.
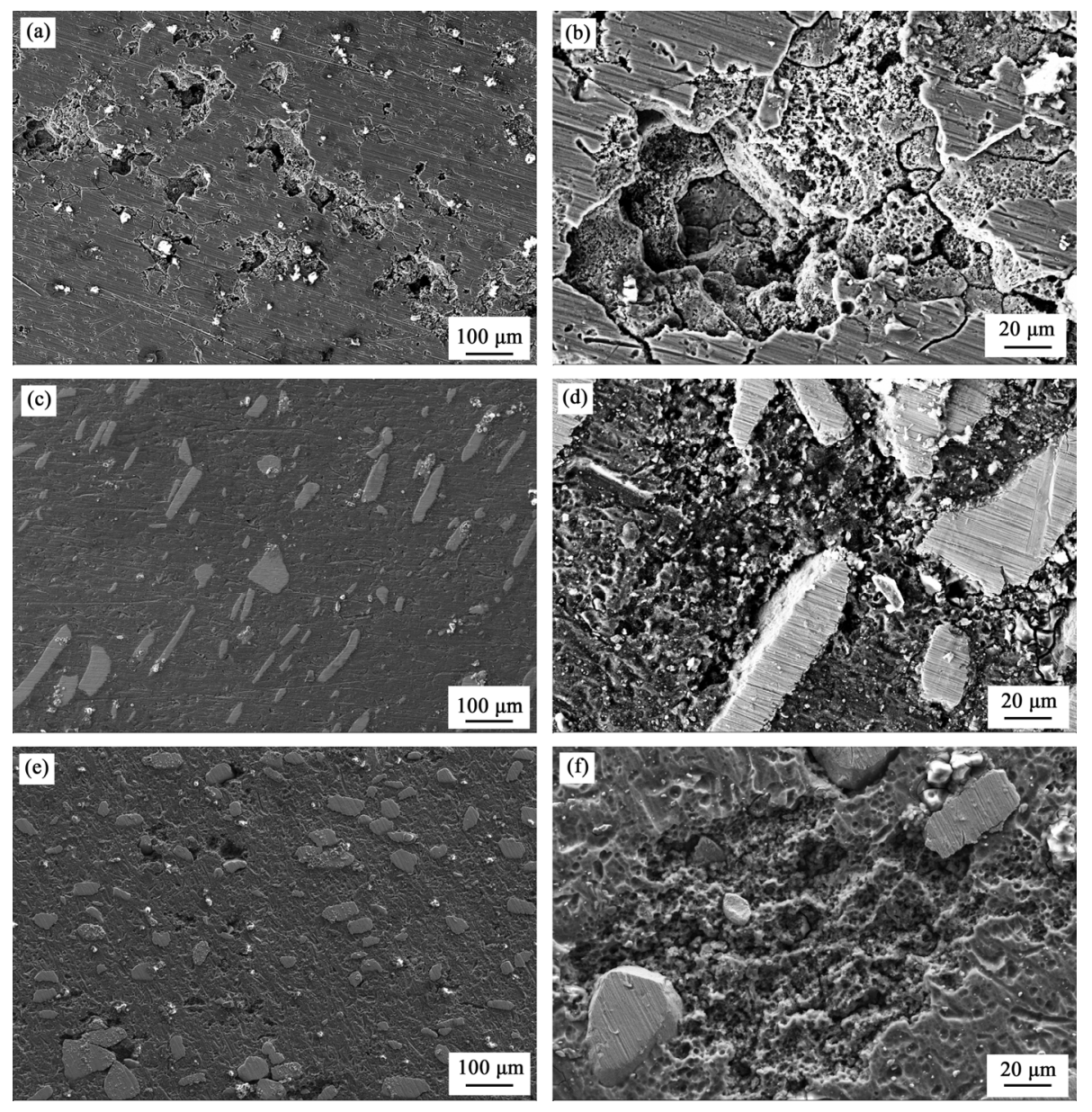

Figure 6. SEM micrographs of electrochemically corroded surfaces: (a and b) S000; (c and d) S300; (e and f) S700.

Figure 7 shows the weight loss of S000, S300, and S700 samples as a function of sliding time. It is observed that their weight losses increase monotonically with the sliding time, and when the sliding time reaches $7 \mathrm{~min}$, the weight loss of S000 increases more quickly than that of S300 and S700. Overall, the wear resistance of three samples are ranked in the order S300 $>$ S700 $>$ S000, which is consistent with their corrosion resistances (Figures 4 and 6). The SEM micrographs of worn tracks of the three samples are shown in Figure 8. The worn surface of the base metal ( $\mathrm{S} 000)$ shows a large amount of plastic flows. The extent of wear in S300 and S700 is lower than that in S000, i.e. their surfaces are smoother and the groove is shallower compared with S000. The higher magnified view of the wear pits shows that the flaking of the base metal is more serious than with the FSP samples, indicating that the worn debris formation is easier at the base metal (Figure 8b,d,f). In addition, there are a lot of fine particles in the size of 
several microns around the $\mathrm{Fe}_{78} \mathrm{Si}_{9} \mathrm{~B}_{13}$ particles (Figure 8d,f) and there exist white particles that impede the worn pit extend along the sliding direction (Figure 8c), indicating that the added $\mathrm{Fe}_{78} \mathrm{Si}_{9} \mathrm{~B}_{13}$ particles play a role in improving the samples' wear resistance.

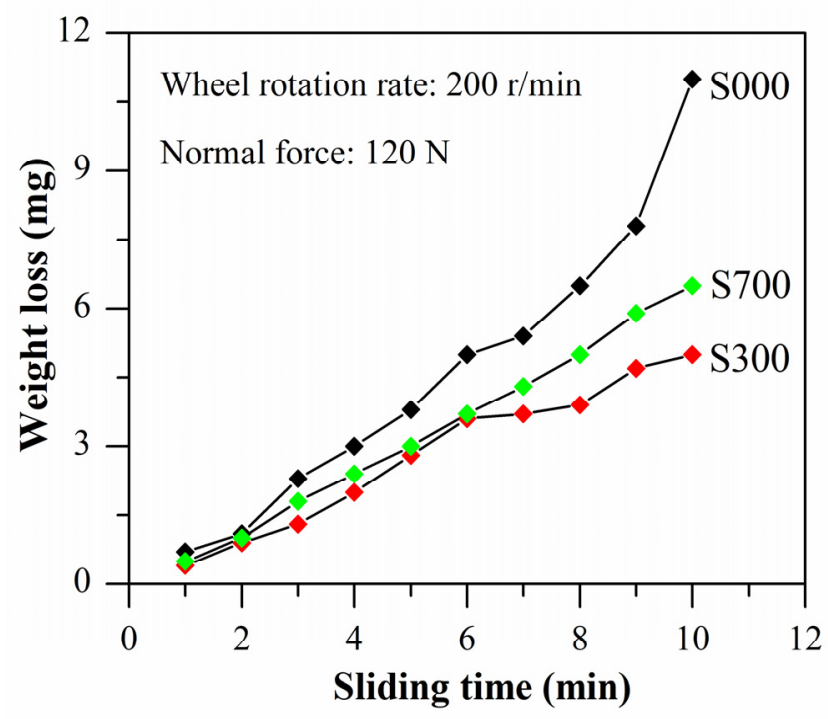

Figure 7. Weight loss of samples as a function of sliding time for base metal (S000) and FSP samples (S300 and S700).
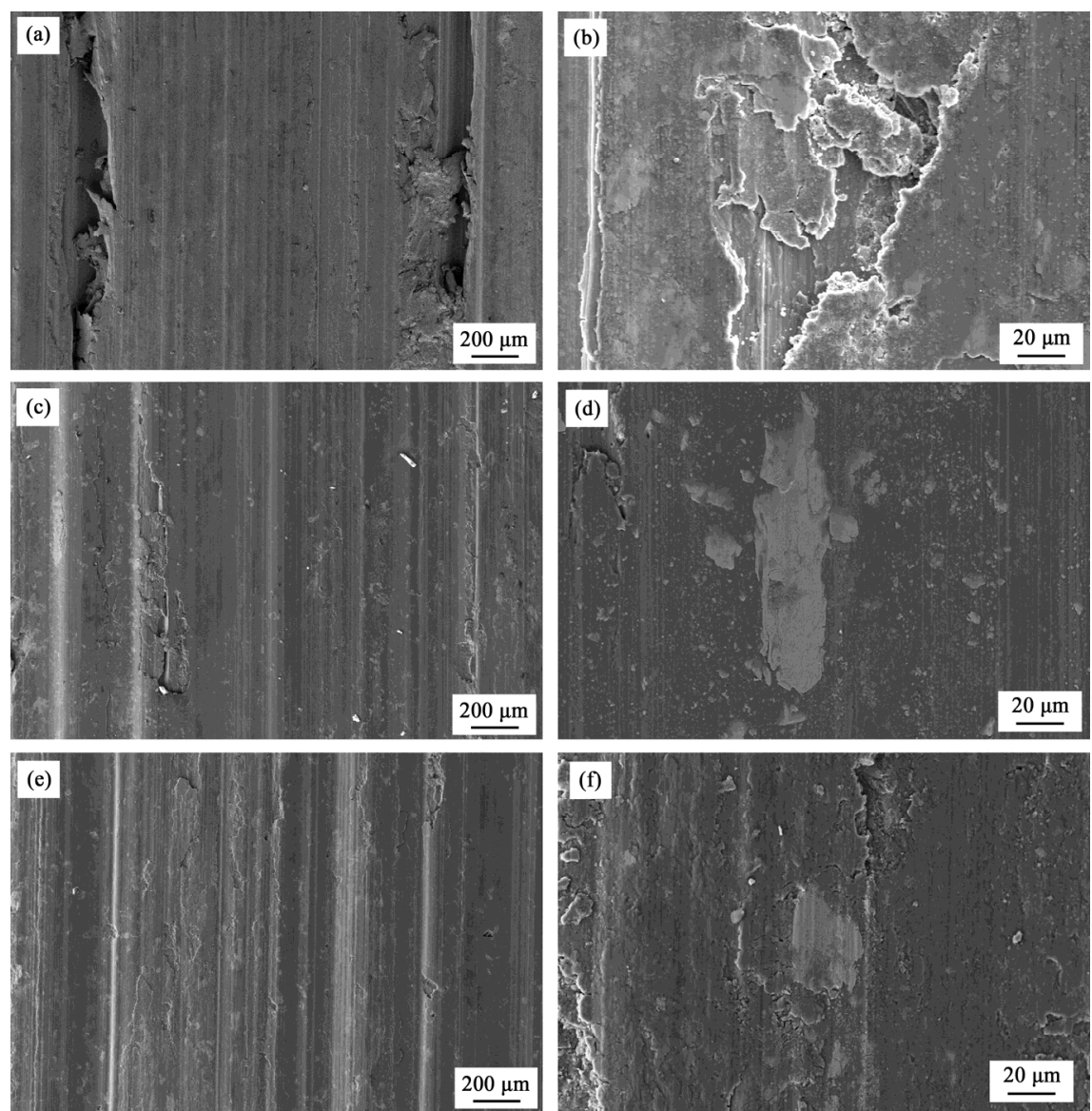

Figure 8. SEM micrographs of worn tracks of samples: (a and b) S000; (c and d) S300; (e and f) S700. 


\section{Discussion}

\subsection{Microstructure and Thermal Expansion Behavior of FSP Samples}

It is well known that grain refinement in metals and alloys can be realized by friction stir processing (FSP), which was derived based on the principles of friction stir welding (FSW) $[9,10]$ and is similar to the grain refining effect of severe plastic deformation (SPD) [24]. Hence, FSP can be considered one of the variants of the severe plastic deformation (SPD) technologies, which is also discussed in recent reports $[25,26]$. It has been reported that the SPD treatment accelerates the atomic diffusion inside the processed material, which attributes to the intensive vacancy generation during deformation [27-29]. Moreover, the solvus temperature of needle-shape precipitate $\left(\beta^{\prime \prime}\right)$ in 6061 aluminum alloys is about $353^{\circ} \mathrm{C}$, which is lower than the maximal temperature during FSP [30], so the $\beta$ " can easily dissolve into the matrix during FSP. In addition, the $\beta$ " mainly contains $\mathrm{Mg}$ and $\mathrm{Si}$ atoms and the dissolution of $\mathrm{Mg}$ and $\mathrm{Si}$ into aluminum matrix could increase the lattice constant of $\alpha-\mathrm{Al}$ [31], thus it is understood that the lattice parameters of S300 and S700 increase after FSP compared with S000 (Figure 2 inset and Table 1). Furthermore, it is reported that the initial rolling texture is destroyed by the deformation during the FSP [32-34]. It is explained that the preferred orientation factor $F$ of the (200) plane in $\alpha$-Al for S300 and S700 is higher than that of S000 (Figure 2 and Table 1).

In the $\mathrm{S} 300$ sample, the $\mathrm{Fe}_{78} \mathrm{Si}_{9} \mathrm{~B}_{13}$ particles annealed at $300{ }^{\circ} \mathrm{C}$ are in the amorphous state, while the $\mathrm{Fe}_{78} \mathrm{Si}_{9} \mathrm{~B}_{13}$ particles have crystallized completely during the annealing process at $700{ }^{\circ} \mathrm{C}$ (Figure $1 \mathrm{~b}$ ). In the amorphous state, the atoms are metastable and in a random order [19], therefore the $\mathrm{Si}$ in $\mathrm{Fe}_{78} \mathrm{Si}_{9} \mathrm{~B}_{13}$ is apt to dissolve into the aluminum matrix and form a solid solution during FSP. Furthermore, the dissolution of Si could also induce severe lattice distortion and dislocation, which may lead to the dissolution of more $\mathrm{Mg}$ and $\mathrm{Si}$ into the aluminum matrix. In the S700 sample, the influence of the $\mathrm{Fe}_{78} \mathrm{Si}_{9} \mathrm{~B}_{13}$ particle annealed at $700{ }^{\circ} \mathrm{C}$ on the lattice parameter is weaker due to its crystalline structure. As a consequence, the lattice constant $a_{0}$ of $\alpha-\mathrm{Al}$ in S300 is larger than that in S700 (Table 1). Meanwhile, compared with S700, the lower $F$ of S300 indicates a severer recrystallization and then a severer destruction of rolling texture, which may result in a severer lattice distortion and dislocation in $\mathrm{S} 300$ and a higher dissolution degree of $\mathrm{Mg}$ and $\mathrm{Si}$. This is also confirmed by the fact that the $a_{0}$ of $\alpha-\mathrm{Al}$ in S300 is higher than that in S700 (Table 1).

According to the micro-mechanical model [35], the initial compression stress of a sample induced by CTE mismatch of the constituents is relieved with increasing temperature and causes an increment in the coefficient of thermal expansion (CTE). We determined the initial increment of CTE of the three measured samples (Figure 3). Furthermore, the CTEs for the three samples increase at first, which is also related to the dissolution of the $\beta$ or $\beta$ " phase, which mainly contains $\mathrm{Mg}$ and $\mathrm{Si}$ due to the positive contribution of $\mathrm{Mg}$ to CTE and $a_{0}$ of $\alpha$-Al solution [31,36,37]. During the cooling process after FSP, the shrinkage degree of base metal was larger than that of the reinforced particles, because the CTE of added particles is less than that of the aluminum matrix alloy, resulting in compressive stress in both the base metal and the added particles [38]. It is understood that the initial CTE of S300 and S700 is lower, and the CTE increment in the beginning stage is higher compared with S000 (Figure 3). Moreover, the maximal CTEs for S300 and S700 are $2.87 \times 10^{-5} \mathrm{~K}^{-1}$ and $3.04 \times 10^{-5} \mathrm{~K}^{-1}$, respectively, and the first maximal of S000 is $2.71 \times 10^{-5} \mathrm{~K}^{-1}$, which is lower than the former values, indicating a higher ability to 
dissolve $\mathrm{Mg}$ for S300 and S700. This is consistent with the $a 0$ variation of measured samples (Table 1). In addition, the temperature at which the CTE begins to decrease for S300 is higher than that for S700, which is due to increased $\mathrm{Mg}$ dissolution into the matrix during FSP for S300, which is also reflected in the data of lattice parameters (Table 1). The decrease of CTE for FSP samples after the maximal CTE is related to the Si dissolution into the matrix, supplied by $\mathrm{Fe}_{78} \mathrm{Si}_{9} \mathrm{~B}_{13}$ particles with a negative contribution to CTE of matrix [39]. Moreover, at $550{ }^{\circ} \mathrm{C}$, the CTE of S300 is lower than that of S000 and S700, which is related to shrinkage of the amorphous $\mathrm{Fe}_{78} \mathrm{Si}_{9} \mathrm{~B}_{13}$ particles in $\mathrm{S} 300$ crystallized during heat processing.

\subsection{Corrosion and Wear Behavior of FSP Samples}

After friction stir processing (FSP), the grain size decreased due to dynamic recrystallization [34], which occurs early on in the alloys after SPD [40,41]. The dynamic recrystallization process has undergone a series of paths [42], which involves the dissolution introduction, dynamic recovery, and continuous dynamic recrystallization. It has been reported that the decrease of grain size can reduce the corrosion rate, that is, it improves the corrosion resistance, which is attributed to an ability of fine-grained materials to passivate more readily and to physical breakdown in the second phase of the intermetallic particles that operated as efficient local cathodes and sites for initiation of localized attack [43,44]. Due to the decrease of grain size by dynamic recrystallization during FSP [33,34], the FSP will improve the corrosion resistance of the aluminum alloy, which is in accordance with Rao's research [45]. On the other hand, in the weld head and its vicinity the residual FSP stresses are either parallel or perpendicular to the weld direction; these are compressive stresses due to the CTE mismatch between the base metal and particles $[38,46]$. The compressive residual stress can improve the corrosion resistance of the surface by reducing the tendency of cracking $[34,47,48]$. Hence, S300 and S700 have more positive $E_{\text {pit }}$ and $E_{\mathrm{pp}}$ than S000 and fewer cracks than S000 (Figures 4-6). Because the CTE of $\mathrm{Fe}_{78} \mathrm{Si}_{9} \mathrm{~B}_{13}$ in the amorphous state is less than that in the crystallized state [38], the S300 endured larger compressive stress than S700. Moreover, it has been reported that the amorphous samples have a better corrosion resistance than the crystallized ones $[49,50]$. Hence, it appears that $\mathrm{S} 300$ has more positive $E_{\text {corr, }} E_{\mathrm{pit}}$, and $E_{\mathrm{pp}}$ than $\mathrm{S} 700$ (Figures 4-6).

The presence of added particles converting the wear mode of FSP samples from two bodies to three bodies reduces the loss of wear further by acting as a solid lubricant [5,14,51]. Apparently, the fine powders of the size of several microns around the $\mathrm{Fe}_{78} \mathrm{Si}_{9} \mathrm{~B}_{13}$ particles possibly act as lubricants (Figure 8d,f). In addition, the residual stress after FSP is compressive stress [46], and moderate levels of compressive residual stress have beneficial effects on wear resistance by delaying crack initiation and growth [52]. Furthermore, the smaller grain was conducive to formation of a tribological transformed structure (TTS) layer, and produced shorter delamination cracks in the TTS layer than the larger one [53] - that is, the ultrafine-grained microstructures exhibit markedly enhanced wear resistance relative to the coarse-grained counterpart. Consequently, for the particles located at the end of worn pits, the wear loss of S300 and S700 is lower than S000 (Figure 7). It is known that the amorphous $\mathrm{Fe}_{78} \mathrm{Si}_{9} \mathrm{~B}_{13}$ is metastable and has a drastic stress-induced flow at about $400^{\circ} \mathrm{C}$ during the heating process [19,54], which possibly accounts for it acting as a better lubricant (Figure 7). As discussed previously, the difference of CTE for added particles leads to a larger compressive stress in S300 than in S700. Hence, it is shown that S300 
has better wear resistance than S700 (Figure 7). In other words, amorphous $\mathrm{Fe}_{78} \mathrm{Si}_{9} \mathrm{~B}_{13}$-reinforced particles can improve the wear and corrosion resistance of AA6061 samples.

\section{Conclusions}

The microstructure, thermal expansion behavior, corrosion behavior and, wear resistance of AA6061-T6 with $\mathrm{Fe}_{78} \mathrm{Si}_{9} \mathrm{~B}_{13}$ glass particles by friction stir processing have been investigated (the base metal is denoted as S000, and the FSP samples with the reinforced particles annealed at $300{ }^{\circ} \mathrm{C}$ and $700{ }^{\circ} \mathrm{C}$ are denoted as S300 and S700, respectively), and it was found that:

(1) By friction stir processing, the $\mathrm{Fe}_{78} \mathrm{Si}_{9} \mathrm{~B}_{13}$ particles are relatively uniform in terms of their dispersion into the $\mathrm{Al}$ alloy matrix. The $a_{0}$ of $\alpha$-Al for three samples is in the order $\mathrm{S} 300>\mathrm{S} 700>\mathrm{S} 000$, but the $F_{200}$ for samples is the opposite. During the heating process, the CTEs of the three samples increase firstly and have a maximal value of $2.71 \times 10^{-5} \mathrm{~K}^{-1}, 2.87 \times 10^{-5} \mathrm{~K}^{-1}$, and $3.04 \times 10^{-5} \mathrm{~K}^{-1}$ for S000, S300, and S700, respectively. The CTE variation can be explained by the dissolving of $\mathrm{Mg}$ and $\mathrm{Si}$ from the $\beta$ phase and $\mathrm{Fe}_{78} \mathrm{Si}_{9} \mathrm{~B}_{13}$ particles, as well as the CTE mismatch compressive stress.

(2) The $E_{\text {corr }}$ and $E_{\text {pit }}$ of the three samples are also in the order S300 $>\mathrm{S} 700>\mathrm{S} 000$, while $i_{\text {corr }}$ is quite the opposite. The superior corrosion resistance for $\mathrm{S} 300$ can be attributed to the reduction of grain size by FSP and the unique metastable structure of amorphous $\mathrm{Fe}_{78} \mathrm{Si}_{9} \mathrm{~B}_{13}$-reinforced particles. Moreover, the corrosion surface of S300 and S700 has little corrosion pits, but no apparent cracking compared to S000.

(3) The wear resistance of FSP samples has been improved compared with the base metal; in particular, the weight loss for the samples is in the order S300<S700<S000. The flaking of S000 after a wear test is more serious than that in S300 and S700. In addition, the worn surfaces of FSP samples are smoother and the grooves shallower compared with S000. The partial improvement of corrosion and wear resistance is ascribed to the compressive stress in FSP samples due to the CTE mismatch between the base metal and reinforced particles, and the lubrication effect of $\mathrm{Fe}_{78} \mathrm{Si}_{9} \mathrm{~B}_{13}$ particles also plays a role in improving wear resistance.

\section{Acknowledgments}

This work is supported by the National Natural Science Foundation of China (Grants No. 51171091, 51471099), the Excellent Youth Project of Natural Science Foundation of Shandong (No. JQ201012), and the National Basic Research Program of China (973 Program) (No. 2012CB825702).

\section{Author Contributions}

Lingyu Guo performed the experiments, analyzed the data, and wrote the initial draft of the manuscript; Weimin Wang designed the project, reviewed and contributed to the final revised manuscript; Yan Liu, Kechang Shen, and Kibuem Kim provided helpful feedback and commented on the manuscript; Min Yang and Chaoqun Song performed the experiments and contributed equipment. All authors read the final paper.

\section{Conflicts of Interest}

The authors declare no conflict of interest. 


\section{References}

1. Bakes, H.; Benjamin, D. Metals Handbook; ASM international: Metal Park, OH, USA, 1979.

2. Vasudevan, A.K.; Doherty, R.D. Aluminum Alloys-Contemporary Research and Applications: Contemporary Research and Applications; Elsevier: Amsterdam, The Netherland, 2012.

3. Ravi, N.; Sastikumar, D.; Subramanian, N.; Nath, A.K.; Masilamani, V. Microhardness and Microstructure Studies on Laser Surface Alloyed Aluminum Alloy with Ni-Cr. Mater. Manuf. Process. 2000, 15, 395-404.

4. Miracle, D.B. Metal matrix composites-From science to technological significance. Compos. Sci. Technol. 2005, 65, 2526-2540.

5. Shafiei-Zarghani, A.; Kashani-Bozorg, S.F.; Zarei-Hanzaki, A. Microstructures and mechanical properties of $\mathrm{Al} / \mathrm{Al}_{2} \mathrm{O}_{3}$ surface nano-composite layer produced by friction stir processing. Mater. Sci. Eng. A 2009, 500, 84-91.

6. Budinski, K.G. Surface Engineering for Wear Resistance; Prentice Hall: Upper Saddle River, NJ, USA, 1988.

7. Mabhali, L.; Pityana, S.L.; Sacks, N. Laser Surface Alloying of Aluminum (AA1200) with Ni and SiC Powders. Mater. Manuf. Process. 2010, 25, 1397-1403.

8. Gupta, M.; Mohamed, F.A.; Lavernia, E.J. Solidification behavior of AI-Li-SiCp MMCs processed using variable co-deposition of multi-phase materials. Mater. Manuf. Process. 1990, 5, 165-196.

9. Mishra, R.S.; Mahoney, M.W.; McFadden, S.X.; Mara, N.A.; Mukherjee, A.K. High strain rate superplasticity in a friction stir processed $7075 \mathrm{Al}$ alloy. Scripta Mater. 1999, 42, 163-168.

10. Mishra, R.S.; Ma, Z.Y.; Charit, I. Friction stir processing: A novel technique for fabrication of surface composite. Mater. Sci. Eng. A 2003, 341, 307-310.

11. Ma, Z.Y. Friction stir processing technology: A review. Metall. Mater. Trans. A 2008, 39, 642-658.

12. Aruri, D.; Adepu, K.; Adepu, K.; Bazavada, K. Wear and mechanical properties of 6061-T6 aluminum alloy surface hybrid composites $\left[(\mathrm{SiC}+\mathrm{Gr})\right.$ and $\left.\left(\mathrm{SiC}+\mathrm{Al}_{2} \mathrm{O}_{3}\right)\right]$ fabricated by friction stir processing. J. Mater. Process. Tech. 2013, 2, 362-369.

13. Clyne, T.W.; Withers, P.J.; Minges, M.L. An Introduction to Metal Matrix Composites; Cambridge University Press: Cambridge, UK, 1995.

14. Ahlatci, H.; Ko Er, T.; Candan, E.; Imeno Lu, H. Wear behaviour of $\mathrm{Al} /\left(\mathrm{Al}_{2} \mathrm{O}_{3} \mathrm{p}+\mathrm{SiCp}\right)$ hybrid composites. Tribol. Int. 2006, 39, 213-220.

15. Liu, Z.Y.; Xiao, B.L.; Wang, W.G.; Ma, Z.Y. Tensile strength and electrical conductivity of carbon nanotube reinforced aluminum matrix composites fabricated by powder metallurgy combined with friction stir processing. J. Mater. Sci. Technol. 2014, 30, 649-655.

16. Makino, A.; Kubota, T.; Chang, C.; Makabe, M.; Inoue, A. FeSiBP bulk metallic glasses with high magnetization and excellent magnetic softness. J. Magn. Magn. Mater. 2008, 320, 2499-2503.

17. Makino, A.; Kubota, T.; Makabe, M.; Chang, C.T.; Inoue, A. FeSiBP metallic glasses with high glass-forming ability and excellent magnetic properties. Mater. Sci. Eng. B 2008, 148, 166-170.

18. Inoue, A. Stabilization of metallic supercooled liquid and bulk amorphous alloys. Acta Mater. 2000, 48, 279-306.

19. Luborsky, F.E. Amorphous Metallic Alloys; Butterworth and Co.: London, UK, 1983.

20. Davis, J.R. Aluminum and Aluminum Alloys; ASM international: Metal Park, OH, USA, 1993. 
21. Zhou, Y. Materials Analysis and Testing Technology; Harbin Institute of Technology Press: Harbin, China, 2007.

22. Lotgering, F.K. Topotactical reactions with ferrimagnetic oxides having hexagonal crystal structures-I. J. Inorg. Nucl. Chem. 1959, 9, 113-123.

23. Wilde, B.E.; Williams, E. The use of current/voltage curves for the study of localized corrosion and passivity breakdown on stainless steels in chloride media. Electrochim. Acta 1971, 16, 1970-1985.

24. Azushima, A.; Kopp, R.; Korhonen, A.; Yang, D.Y.; Micari, F.; Lahoti, G.D.; Groche, P.; Yanagimoto, J.; Tsuji, N.; Rosochowski, A. Severe plastic deformation (SPD) processes for metals. CIRP Ann. Manuf. Technol. 2008, 57, 716-735.

25. Nikulin, I.; Malopheyev, S.; Kipelova, A.; Kaibyshev, R. Effect of SPD and friction stir welding on microstructure and mechanical properties of Al-Cu-Mg-Ag sheets. Mater. Lett. 2012, 66, 311-313.

26. Raj, K.H.; Sharma, R.S.; Singh, P.; Dayal, A. Study of friction stir processing (FSP) and high pressure torsion (HPT) and their effect on mechanical properties. Proc. Eng. 2011, 10, 2904-2910.

27. Mazilkin, A.A.; Straumal, B.B.; Rabkin, E.; Baretzky, B.; Enders, S.; Protasova, S.G.; Kogtenkova, O.A.; Valiev, R.Z. Softening of nanostructured Al-Zn and Al-Mg alloys after severe plastic deformation. Acta Mater. 2006, 54, 3933-3939.

28. Straumal, B.B.; Mazilkin, A.A.; Baretzky, B.; Schütz, G.; Rabkin, E.; Valiev, R.Z. Accelerated diffusion and phase transformations in $\mathrm{Co}-\mathrm{Cu}$ alloys driven by the severe plastic deformation. Mater. Trans. 2012, 53, 63-71.

29. Straumal, B.B.; Gornakova, A.S.; Mazilkin, A.A.; Fabrichnaya, O.B.; Kriegel, M.J.; Baretzky, B.; Jiang, J.Z.; Dobatkin, S.V. Phase transformations in the severely plastically deformed Zr-Nb alloys. Mater. Lett. 2012, 81, 225-228.

30. Sato, Y.S.; Kokawa, H.; Enomoto, M.; Jogan, S.; Hashimoto, T. Precipitation sequence in friction stir weld of 6063 aluminum during aging. Metall. Mater. Trans. A 1999, 30, 3125-3130.

31. Steuwer, A.; Dumont, M.; Peel, M.; Preuss, M.; Withers, P.J. The variation of the unstrained lattice parameter in an AA7010 friction stir weld. Acta Mater. 2007, 55, 4111-4120.

32. Woo, W.; Choo, H.; Brown, D.W.; Vogel, S.C.; Liaw, P.K.; Feng, Z. Texture analysis of a friction stir processed 6061-T6 aluminum alloy using neutron diffraction. Acta Mater. 2006, 54, 3871-3882.

33. El-Danaf, E.A.; El-Rayes, M.M.; Soliman, M.S. Friction stir processing: An effective technique to refine grain structure and enhance ductility. Mater. Design 2010, 31, 1231-1236.

34. Woo, W.; Balogh, L.; Ungár, T.; Choo, H.; Feng, Z. Grain structure and dislocation density measurements in a friction-stir welded aluminum alloy using X-ray peak profile analysis. Mater. Sci. Eng. A 2008, 498, 308-313.

35. Huber, T.; Degischer, H.P.; Lefranc, G.; Schmitt, T. Thermal expansion studies on aluminium-matrix composites with different reinforcement architecture of $\mathrm{SiC}$ particles. Compos. Sci. Technol. 2006, 66, 2206-2217.

36. Uju, W.A.; Oguocha, I.N.A. A study of thermal expansion of Al-Mg alloy composites containing fly ash. Mater. Design 2012, 33, 503-509.

37. Berry, C.R. Effect of internal strains on linear expansion, X-Ray lattice constant, and density of crystals. J. Appl. Phys. 1953, 24, 658-659.

38. Ma, H.J.; Zhang, J.T.; Li, G.H.; Zhang, W.X.; Wang, W.M. Effect of Zr on the thermal stability and magnetic properties of $\mathrm{Fe}_{78} \mathrm{Si}_{9} \mathrm{~B}_{13}$ glassy alloy. J. Alloy. Compd. 2010, 501, 227-232. 
39. Zhang, Q.; Wu, G.; Jiang, L.; Chen, G. Thermal expansion and dimensional stability of Al-Si matrix composite reinforced with high content SiC. Mater. Chem. Phys. 2003, 82, 780-785.

40. Straumal, B.B.; Protasova, S.G.; Mazilkin, A.A.; Rabkin, E.; Goll, D.; Schütz, G.; Baretzky, B.; Valiev, R.Z. Deformation-driven formation of equilibrium phases in the $\mathrm{Cu}-\mathrm{Ni}$ alloys. J. Mater. Sci. 2012, 47, 360-367.

41. Straumal, B.B.; Dobatkin, S.V.; Rodin, A.O.; Protasova, S.G.; Mazilkin, A.A.; Goll, D.; Baretzky, B. Structure and properties of nanograined Fe-C alloys after severe plastic deformation. Adv. Eng. Mater. 2011, 13, 463-469.

42. Su, J.Q.; Nelson, T.W.; Mishra, R.; Mahoney, M. Microstructural investigation of friction stir welded 7050-T651 aluminium. Acta Mater. 2003, 51, 713-729.

43. Ralston, K.D.; Birbilis, N.; Davies, C.H.J. Revealing the relationship between grain size and corrosion rate of metals. Scripta Mater. 2010, 63, 1201-1204.

44. Ralston, K.D.; Birbilis, N. Effect of grain size on corrosion: A review. Corrosion 2010, 66, 1201-1204.

45. Rao, A.G.; Katkar, V.A.; Gunasekaran, G.; Deshmukh, V.P.; Prabhu, N.; Kashyap, B.P. Effect of multipass friction stir processing on corrosion resistance of hypereutectic Al-30Si alloy. Corros. Sci. 2014, 83, 198-208.

46. Staron, P.; KoçAk, M.; Williams, S.; Wescott, A. Residual stress in friction stir-welded Al sheets. Physica B 2004, 350, E491-E493.

47. Van Boven, G.; Chen, W.; Rogge, R. The role of residual stress in neutral pH stress corrosion cracking of pipeline steels. Part I: Pitting and cracking occurrence. Acta Mater. 2007, 55, 29-42.

48. Prevey, P.; Cammett, J. The influence of surface enhancement by low plasticity burnishing on the corrosion fatigue performance of AA7075-T6. Int. J. Fatigue 2004, 26, 975-982.

49. Tam, M.K.; Shek, C.H. Crystallization and corrosion resistance of $\mathrm{Cu}_{50} \mathrm{Zr}_{45} \mathrm{Al}_{5}$ bulk amorphous alloy. Mater. Chem. Phys. 2006, 100, 34-37.

50. Naka, M.; Hashimoto, K.; Masumoto, T. Corrosion behavior of amorphous and crystalline $\mathrm{Cu}_{50} \mathrm{Ti}_{50}$ and $\mathrm{Cu}_{50} \mathrm{Zr}_{50}$ alloys. J. Non-Cryst. Solids 1978, 30, 29-36.

51. Gurcan, A.B.; Baker, T.N. Wear behaviour of AA6061 aluminium alloy and its composites. Wear 1995, 188, 185-191.

52. Mohammadzadeh, R.; Akbari, A.; Drouet, M. Microstructure and wear properties of AISI M2 tool steel on RF plasma nitriding at different $\mathrm{N}_{2}-\mathrm{H}_{2}$ gas compositions. Surf. Coat. Technol. 2014, 258, $566-573$.

53. Li, J.; Lu, Y.; Zhang, H.; Xin, L. Effect of grain size and hardness on fretting wear behavior of Inconel 600 alloys. Tribol. Int. 2015, 81, 215-222.

54. Niu, Y.C.; Bian, X.F.; Wang, W.M.; Jin, S.F.; Liu, X.J.; Zhang, J.Y.; Qin, G.L. The use of flow behavior and thermal expansion to monitor structural change of amorphous $\mathrm{Fe}_{78} \mathrm{Si}_{9} \mathrm{~B}_{13}$ ribbon. J. Non-Cryst. Solids 2005, 351, 3854-3860.

(C) 2015 by the authors; licensee MDPI, Basel, Switzerland. This article is an open access article distributed under the terms and conditions of the Creative Commons Attribution license (http://creativecommons.org/licenses/by/4.0/). 